\title{
Research on Online Public Opinion Management Mechanism Based
}

\section{on Social Management Innovation}

\author{
Huang Yuwen ${ }^{1}$ Song Guangxing ${ }^{2}$ \\ ${ }^{1,2}$ School of Public Management, Yunnan University of Finance and Economics, \\ Kunming, P.R.China, 650221 \\ (hy5w@163.com,gxsong_yn@163.com)
}

\begin{abstract}
The management of virtual society is an important part of social management, and the management of online public opinion plays an important role in management innovation of virtual society. Thus, promoting the management of online public opinion is particularly important and urgent for the management innovation of virtual society. This paper analyzes relevant characteristics of online public opinion, expound its influence on the society, and finally make proposals for the management of online public opinion from the perspective of social management innovation.
\end{abstract}

Keywords: Virtual Society, Network, Social Management, Online Public Opinion

\section{Introduction}

With the development of information technology and the popularity of Internet technology, earth-shaking changes have happened to people's life and production method. The change of these traditional behaviors and habits deeply influence all aspects of the Chinese society, and the realistic society obtains further continuation and extension with the action of the Internet. At present, the network society has become an important platform in people's life and it provides broad space for human society's ideological and cultural communication as well as social activities. The statistical investigation results of CNNIC have shown: the popularity rate of Internet in China had reached $42.1 \%$ by 2013; In the meantime, the total number of netizens had increased to 564 million; Besides, the size of mobile phone netizens in China have reached 420 million. [1] With the popularity of the Internet, the influence of online media also upgraded rapidly, broke through the bottleneck of traditional media, and became the core of information dissemination. Now, more and more netizens begin to use the Internet to express their ideas and inner appeals, so network provides a broad space and platform for all citizens to express their public opinions. Sprouting and growing up under such overall background, online public opinion makes new requests for social management in China. In the Report of the $18^{\text {th }}$ CPC National Congress, the Central Government explicitly indicated that we should "accelerate the formation of scientific and effective social management system and strengthen and improve network construction". While virtual society management is a vital composition of social management, online public opinion management has great effect on virtual society management innovation. Currently, the research on online public opinion of academic circles mainly concentrates on aspects such as the concept, characteristics, formation mechanism of online public opinion, as well as its guiding, controlling and early warning mechanism. In general, it mainly focuses on some aspect of online public opinion, but pays less attention to its overall situation. This paper plans to research the management of online public opinion on the whole from the perspective of social management innovation.

\section{Online Public Opinion and Its Characteristics}

Up to now, there is not yet a uniform definition about online public opinion. Liu Yi (2007) argued that online public opinion referred to the sum of the public's different viewpoints, attitudes and opinions about something published and disseminated online.[2] Zhou Rujun (2005) argued that online public opinion referred to the social public's opinions or speeches with some influence and tendency about some "focus" and "hotspot" spreading on the Internet.[3] Besides, foreign scholars also make definition about online public opinion 
from different perspectives. Herbert Blumer (1947) argued that online public opinion was a kind of collective acts made up by discussers at anytime in specified public place. Laihua et al argued that online public opinion referred to the political attitude toward the society and social managers in certain social space.[4] This paper argues that online public opinion refers to the sum of netizens' viewpoints, suggestions and feelings about various social phenomena and problems in certain cyber space. Due to the form diversification of the overall network, the manifestation pattern of public opinion is also verified, including BBS, post reply, microblog, e-mail, etc. In general, the power of online public opinion can be maximized after an online popular event or a piece of special news is exposed. In terms of the form of overall communication, it shows the following characteristics:

Firstly, online public opinion is featured with abundance information, rapid propagation speed, and wide range of influence. Compared with traditional information channels, it is of the characteristics of rapid response and inexpensive cost, and online information is not restricted to channel, time and space. Besides, its content covers a wide range, including politics, economy, culture, etc. The Internet can adopt multiple channels for information dissemination. With the technology of online hyperlink, a great deal of public information can be searched, disseminated, and fed back at any time. Thus, the amount and speed of online public information publication will surpass that of other media in realistic society.

Secondly, online public opinion is featured with non-rationality. In some way, online public opinion can be regarded as netizens' catharsis, so it is of strong non-rationality. Large numbers of frustrated groups can't release their negative mood in life, so they may give vent to their feelings online without scruple. Under the protection of the Internet, these exaggerated, bizarre and strongly seditious subjects may easily arouse people's sympathy and then become the hot topics in the society, so as to give rise to interaction among netizens, and as a result, various contradictions and problems are gathered and magnified online.

Thirdly, online public opinion is featured with instantaneity. The Internet is open, and speeches can be published by signature or anonymously. Without procedures such as "agenda setting” and "gate-keeper" of traditional media operation, speeches expressed online can be disseminated instantly. Besides, the usage of network is not restricted to time and place, so public opinion formed online can be searched and followed up by network users at any time and place, and new public opinion also can be discovered by users instantly,[5] so that more public information will be exposed.

\section{Influence of Online Public Opinion on the Society}

The rapid development of information technology and the Internet makes network become the important channel for netizens to express their various appeals, and social information and public will are concentrated online. Meanwhile, as the Internet becomes an occasion for people to express their dissatisfaction with social phenomena, network platform even becomes the stage full of games about various thoughts, ideologies and political ideas. The power of network become more and more important in social management, but it's noteworthy that online public opinion is a double-edged sword, so both advantages and disadvantages of online public opinion should be understood correctly.

\subsection{Positive Effects of Online Public Opinion}

\section{on the Society}

Online public opinion is an important channel of public appeal in constructing harmonious society and becomes important force in social construction and management, which is mainly reflected in:

\subsubsection{Promoting the Settlement of Social Events}

The development of information technology and Internet makes the quantity and quality of Chinese netizens increased rapidly, and people can participate in the public affairs of the government through the Internet. From this perspective, it can be seen that online public opinion can promote the settlement of sharp social problems to different degrees. In 2006, the Chinese Central Government built its portal website and started officially making use of the Internet to solicit public will widely. Since then, local governments at all levels began to build their own portal websites in succession, which aroused close attention of wide netizens. Netizens could express their own opinions against various social events; In the meantime, all portal websites could also carry out opinion survey about relevant problems among wide netizens, so that the public will could be well expressed. According to current online anti-corruption event, a series of officials such as "elder male cousin", "house uncle”, "house madam", etc. have been suspended from office because of online report. The Peoples and Peoples Daily carried out investigation about 
these events, and their investigation results have showed that $68 \%$ netizens would most like to participate in anti-corruption by means of online exposure, and $87 \%$ of them would choose anonymous reporting. It is thus clear that when online public opinion exposes some social problems, it greatly drives the development of events, so that the public appeals are delivered through the Internet.

\subsubsection{Encourage the Government to Improve Its Working Style}

The freedom and openness of online media is different from the hegemony of traditional media. As online information can be reallocated freely, an era where "everyone is the microphone" has come. In online media, everyone who can use the Internet may become the dominant person of information, and they break the phenomenon of information isolated island and make the information controlled by the government in the past be received by more people, which greatly enhances the supervision of the government and further promotes the masses' right to information. For example, about Wenzhou "7.23" Event, the widespread online information drew relevant departments' great attention. Required by netizens, relevant departments handled that event with positive attitude. In this event, online media took an active part and relevant governmental departments changed their previous working style in wide netizens' appeals. This event fully indicates that online public opinion plays an important role in supervising governmental departments' behavior style and has positive significance to improve their working style.

\subsubsection{Provide Support for the Party and the Government's Scientific Decision- Making}

In general, problems reflected by online public opinion are social focuses that are closely related to the masses and need to be solved. Besides, it is also an important channel for the Party and the government to collect public opinions. At present stage, governments at all levels try to make “online petition”, “online report” and other methods on their portal websites to achieve the conversation with the masses, so that the public can more directly express their opinions and suggestions through online channel. In addition, some governmental officials also publish government information and collect useful information from the masses by means of some newly emerging media such as blog, microblog, etc., to enlarge the public's participation. Only fully understanding the public's real demand can the government's decision better gear to actual circumstances, risk of decision-making failure be lowered, and the government's service efficiency be enhanced practically. When large numbers of food safety events such as "Clenobuterol Hydrochloride”, "Substandard Milk Powder”, “Sudan Red”, etc. aroused great attention and caused free discussion online, they promoted the country to further improve its concern and attention to food safety.

\subsection{Negative Effects of Online Public Opinion on the Society}

The Internet plays an important and active role in promoting China's social management and increasing channels for public opinion expression. However, the other side of the Internal must be paid attention to, for it may have negative effects on social development of China, which are mainly reflected in following aspects:

\subsubsection{Online Public Opinion May Easily Cause Mass Incidents}

Mass incidents exist in both realistic world and virtual Internet. The latter mainly refers to the virtual environment of network. Different netizens would make use of the form of network to mould social public opinions about the same issue online from different viewpoints, in the hope of reaching their own goals. As a result, online mass incidents came into people's sight constantly in recent years.

Currently, the development of market economy and society in China is still at its crucial stage, and interest conflicts among various social groups are increasing significantly. However, there is not yet complete channel for public opinion expression in Chinese society, so social masses can only express their ideas and give vent to their feelings online. Online public opinion is often discussed revolving around various complicated social problems in the society, and it shows the contradiction produced by various superimposed social problems. Generally, online public opinion is netizens' will that can't be expressed by normal channel in realistic society. The accelerating online information dissemination makes online public opinion easily and rapidly spread within a short time, leading to a great deal of discontent. What's worse, as more and more netizens complain about their discontent online, chain reactions will be further brought about.

Online public opinion expression is often irrational and emotional. Different netizens can give comments without scruple online, so that public opinion can be spread rapidly. Netizens' unhealthy emotions will arouse more other netizens' attention, and chain reactions produced will make online public opinion become a powerful force. A part of netizens even organize and make plans in secret, so as to cause 
large-scale online group incidents. If such online group incidents fail to be guided or handled in a proper way, a series of adverse reactions would emerge, so as to further increase harm to the society.

\subsubsection{Online Public Opinion Influences the Normal Operation of the Government}

Le Pen (2012) argued, "In specific case, a part of people would show different characteristics, with obvious distinction from characteristics possessed by the group they are in. The group's idea would turn to the same focus consistently, to produce a kind of collective mind in this group.”[6] This kind of collective opinion will be encouraged and maintained by group members, regardless of its right or wrong. In general, there is no correlation between collective public opinion and rationality, which means that most collective views are wrong. Online public opinion would have great effects on relevant governmental departments' decision-making and bring serious interference to governmental departments' work.

\subsubsection{The Concealment of Online Public Opinion Can Be Easily Used by Hostile Forces}

The anonymity of network allows netizens to make speeches freely without revealing their real information, which may cause some lawbreakers or hostile forces to make use of the concealment of network to publish some information against social stability, even control the social masses and fabricate rumors. Hostile forces can make use of sensitive issues in the society to govern netizens' mood, to cause large numbers of netizens to be dissatisfied with the government and China's political system, which have serious negative effects on the stability of Chinese society.

\section{Countermeasures for Online Public Opinion Management}

Online public opinion is a new challenge faced by our Party and government. Promoting online public opinion management will be of great importance in advancing social management innovation. Thus, how to manage online public opinion becomes particularly important.

\subsection{Intensify Network Legislation and \\ Enhance Netizens' Self-Discipline}

At present, problems such as imperfection and incompatibility exist in the specific implementation of existing laws and regulations on network management, mainly including low legislative level, multifarious departmental rules, insufficient online extension of existing legal resource, and failure of network legislation to meet the demand of development trend. In this regard, developed countries provide precious experience for us. In 1995, the US Government issued Communications Decency Act. The Singapore government provided that all websites of ISPs (Internet Service Provider), party and government organizations in Singapore should be approved, supervised, and managed daily by Singapore Broadcasting Authority. Once information going against social development or endangering the country are discovered, they will be handled immediately. Learning from relevant foreign experience, based on existing laws in China, the Chinese government should establish online public opinion management mechanism, implement special legislative management on the safety of online information, and strictly supervise those contents involving China's politics, nationality and other sensitive topics. In accordance with relevant provisions of the law, it should practically guarantee the normalization of online public opinion expression and promote sound development of online public opinion. Besides, it should achieve the law enforcement of online information management and the timeliness of judicature.

In addition, when establishing online information supervision mechanism, relevant governmental departments should also reinforce the civilization construction of the Internet, make an utmost effort to purify the network environment, encourage netizens to behave in a civilized way, and practically improve their ideological and moral qualities; it should build relevant mechanism for network service, ensure the safety of online information, fully bring the role of related management associations into play, and enhance the safety of online information; it should make every effort to cultivate network users' moral sense and self-discipline consciousness and take correct measures to guide netizens to comply with relevant regulations. Modern socialized media and online media should consciously regulate their behaviors, abide by moral baseline, actively bring healthy information to wide network users, and comprehensively ensure the safety and reality of online information, to promote sound development of online public opinion.

\subsection{Construct Mechanism Coping with \\ Emergent Online Public Opinion Crisis}

In general, online public opinion is always hidden among massive netizens' speeches, so merely relying on traditional artificial interpretation to analyze online public opinion will always get half the result with twice the effort. In particular, it is unrealistic to follow the track of key netizens with traditional artificial 
method. Therefore, the management level of virtual society should be improved and the administration and guidance of online public opinion should be strengthened.

\subsubsection{Construct Governmental Authoritative Information Distribution Mechanism}

Nowadays, as traditional media have lost their leading position, in online media, information receivers gradually start receiving information actively instead of receiving information passively in the past. In addition to receiving information, netizens can also publish relevant information through socialized media such as social network. Relevant governmental departments should keep a positive attitude to guide netizens to receive information in correct way and treat online public opinion with correct value. In the past, when handling social emergencies, the government always considered them from the perspective of stable development of the society, so the information publication always lagged behind. A shortage of this handling way is that it is very difficult to block off information under the background of online media. Thus, governmental departments should actively ensure the public's right to information. Frequently, the silence of a view-holding party will cause the power of the other view-holding party in the formation of public opinion.[8] Thus, the government should establish transparent, timely and effective governmental information publication system, to clarify false rumors and malicious speculation, to win the trust of the people. In particular, when emergencies occur, the government should publish mainstream information the very first time to master the dominant right. Besides, it should also pay attention to the public opinion trend of critical nodes before the event, in the middle of the event, and after the event, to publish the latest information of the event handling, and respond timely to the public's question and speculation. Only publishing authoritative information timely and correctly and compressing the space of false information spreading can it promote its public opinion guidance ability and bring online public will into mainstream public opinion.

\subsubsection{Construct Early-Warning Mechanism of Online Public Opinion}

Public opinion is characterized by contingency. The rapidness of network media can lead to the concentrated outbreak of public opinion in a short time, which proves to be the challenge presented for the management of governmental departments. Therefore, it is necessary to establish a complete intervention system for real-time monitoring of online public opinion, which will thus improve the disposing efficiency. Online early-warning system comprises the main contents such as index, grade, and forecasting method. As a complicated system, early-warning system of online public opinion must be jointly constructed by experts from different domains during the formulation process.

\subsubsection{Set up Search Mechanism of Online}

Public Opinion as Well as Research and Judgment Mechanism of Online Public Opinion

On the whole, online public opinion should be classified into the category of ideological and political work, for which linkage mechanism must be jointly constructed by competent authorities and other related departments. All related departments are required to realize the rapid dissemination of information and the timely disposal of information detected by propaganda department. Research and judgment mechanism of public opinion includes public opinion planning, public opinion collection, public opinion analysis, public opinion control, and public opinion evaluation. Related administrative departments are expected to classify and organize the collected public opinions. Then, these collected information should be analyzed from the aspects such as information viewing, hotspot statistics, key netizens tracing, focus events tracing, and statistics report. Furthermore, research and judgment should be made on the information to take corresponding emergency measures. In the case of major public opinion events, administrative departments are supposed to immediately organize crisis management team to handle crisis events. In case of contingency, all departments should cooperate with each other and pay high attention to it.

\subsubsection{Establish the Supervision and Guidance Mechanism of Public Opinion}

Because of network convenience, the public can learn about the latest information and process of events at the very first time. Via internet, the public can timely grasp the progress of events and the attitude of governmental departments toward events disposal. Internet has developed into the important channel for the public to show concern about focus events. And the public will hold a negative impression of governments departments, if they are incapable of timely publishing related information and disposing measures of events via internet. Meanwhile, if governmental departments block the information or fail to timely release relevant information, more adverse public opinions will be caused, which will thus exert negative influence on social production and stability to varying degrees. Therefore, governmental departments are necessary to establish related mechanism and strengthen the construction of online comment 
block by means of internet. Generally, people tend to select the highly authoritative websites with diverse contents during internet browsing and information searching. Thus, government's network media are supposed to fully play the role of online public opinion guidance, and besides, they are expected to release information with online hot issues as focus, organize online publication of in-depth and convincing papers, reply to questions, and maintain the correct guidance of online public opinion. At the same time, it is necessary to focus attention on network comments and cultivate a group of high-quality and influential online commentators. Additionally, there is a need to take an active part in online follow-up posts and discussions as well as the thoughtful online comments that are really close to reality, life and the masses, which can help to develop a healthy environment of online public opinion gradually.

\subsection{Construct Favorable Interactive Mechanism between Governments and Citizens}

Internet proves to be the source of various kinds of information and the field where different thoughts and ideologies fight against each other. During the process of social management and administration, the proper utilization of this tool has not only related to the credibility of governmental departments in society, but also the construction of China's socialist harmonious society. Therefore, governmental departments are necessary to:

\subsubsection{Expand Approaches for Netizens to Participate in Administration and Discussion of State Affairs}

Governmental departments are needed to construct specialized website and platform for netizens to voice their opinions. Via the official website of governmental departments, netizens can voice their appeals and get timely response about corresponding questions from governmental departments. Governmental departments at all level are supposed to collect the appeals of internet users in various forms, and set up website interactive mechanism of all departments. Meanwhile, they are also expected to make good use of domestic mainstream media, such as www.Xinhuanet.com and www. people.com.cn, and commutate with netizens as much as possible.

\subsubsection{Guide the Rational Participation of Netizens}

Besides convenience and high speed, network shows the biggest feature of virtuality, which is the largest gap between network media and traditional media. On the internet, netizens are allowed to freely voice their opinions, and unbosom themselves, which has enabled the network to become a platform of free exchange and opinion expression. On the internet, some malicious information is often posted, most of which is netizens' irrational remarks. In this way, netizens can express their emotions about the reality, which doesn't really represent individual interests. Thus, governmental departments are required to positively guide the normative behavior of netizens and establish online moral mechanism and enhance netizens' capacity of information identification. The reasonable utilization of internet can capacitate netizens to express their real appeals, rather than to start a rumor or unscrupulously voice their irrational appeals on the internet.

\subsubsection{Improve Leader's Internet Management Capacity}

The increasingly transparent public opinion environment requires that leading cadres should not only have ability of withstanding public opinion pressure and improve coping capacity, but also get accustomed to public information and enhance their ability to research and judge online public opinion.[9] Traditional leading methods are no longer appropriate for the development of online era. Therefore, in internet era, leading cadres are more required to take advantage of internet to understand people's conditions, gather people's wisdom and conciliate public discontent. In this case, online public opinion will play a more effective role in the process of social management of public affairs. Meanwhile, they are also expected to accept social supervision consciously and integrate online public opinion with social management practice, so as to keep improving the social management level of governmental departments.

\section{Conclusions}

Everything is double-sided without exception of online public opinion. For one thing, it has advanced the progress of some aspects such as Chinese politics and economy, while for another, it has resulted in a variety of problems and fierce discussions, thus posing great challenge to social management. From years of practice, it can be seen that the enhancement and innovation of social management contribute greatly to public opinion. Governmental departments are supposed to fully understand the important function of public opinion under new situation, show great concern about public opinion, and go deep into the influence of new media such as internet on governmental work. Additionally, they are expected to make innovations in aspects of ideas, methods and mechanisms and keep 
improving governmental capacity and level. This proves to be the change of government's administrative ideas and methods in internet era and social management's objective requirements of advancing with times.

\section{References}

[1] China Internet Network Information Center (CNNIC). Statistical Report on the Development of the Internet in China, 2012, 12

[2] LiuYi. Introduction to Research on Online Public Opinion [M].Tianjin: Tianjin People’s Publishing House, 2007: 53-55.

[3] Zhou Rujun, Wang Tianqi. Online Public Opinion: a New Field of Modern Ideological and Political Education [J]. Ideology Education, 2005, (11): 12-15.

[4] Herbert Blumer. Public Opinion and Public OpinionPolling [J]. American Sociological Review, 1947, 13 (5): 542-549.

[5] Wang Yin. Research on the Influence of Online Public Opinion on Government Management and Its Coping Mechanism [J]. Economic Research Guide. 2011, (21): 219.

[6] Ye Guoping. View the Persuasion and Solution of Mass Incidents Based on the Influence of Online Public Opinion [J]. Theory and Modernization, 2012, (7): 60

[7] Xun Yao. Public Crisis Events and Online Public Opinion Safety [J]. Heilongjiang Social Science, 2010 (6): 155.

[8] Elisabeth Noelle-Neumann E. The Spiral of Silence: Public Opinion-Our Social [M]. Chicago: University ChicagoPress, second edition, 1993: 50-56.

[9] Zhang Fanghua. Status and Strategy of Chinese Public Opinion Management [J]. Modern Economic Information, 2009, (9): 129 